\title{
Adipose afferent reflex is enhanced by TNFa in paraventricular nucleus through NADPH oxidase-dependent ROS generation in obesity-related hypertensive rats
}

Lei Ding ${ }^{1,2}$, Ying Kang ${ }^{1}$, Hang-Bing Dai ${ }^{1}$, Fang-Zheng Wang ${ }^{1}$, Hong Zhou' ${ }^{1}$, Qing Gao ${ }^{1}$, Xiao-Qing Xiong ${ }^{1}$, Feng Zhang ${ }^{1}$, Tian-Run Song ${ }^{1}$, Yan Yuan ${ }^{1}$, Ming Liu' ${ }^{1}$, Guo-Qing Zhu' ${ }^{1}$ and Ye-Bo Zhou ${ }^{1 *}$ (D)

\begin{abstract}
Background: The adipose afferent reflex (AAR), a sympatho-excitatory reflex, can promote the elevation of sympathetic nerve activity (SNA) and blood pressure (BP). Inflammation in the paraventricular nucleus (PVN) involves sympathetic abnormality in some cardiovascular diseases such as hypertension. This study was designed to explore the effects of tumor necrosis factor alpha (TNFa) in the PVN on the AAR and SNA in rats with obesity-related hypertension $(\mathrm{OH})$ induced by a high-fat diet for 12 weeks.
\end{abstract}

Methods: Renal sympathetic nerve activity (RSNA) and mean arterial pressure (MAP) were continuously recorded in anesthetized rats, and their responses to capsaicin (CAP) stimulation of the right inguinal white adipose tissue were used to evaluate the AAR.

Results: Compared to the control rats, the systolic blood pressure (SBP), plasma norepinephrine (NE, indicating SNA) and TNFa levels, TNFa mRNA and protein levels, reactive oxygen species (ROS) content and NADPH oxidase activity in the PVN were significantly elevated in rats with $\mathrm{OH}$. TNFa in the PVN markedly enhanced sympathoexcitation and AAR. Moreover, the enhancement of AAR caused by TNFa can be significantly strengthened by the pretreatment of diethyldithiocarbamate (DETC), a superoxide dismutase inhibitor, but attenuated by TNF-a receptor antagonist R-7050, superoxide scavenger PEG-SOD and NADPH oxidase inhibitor apocynin (Apo) in rats with OH. Acute microinjection of TNF-a into the PVN significantly increased the activity of NADPH oxidase and ROS levels in rats with OH, which were effectively blocked by R-7050. Furthermore, our results also showed that the increased levels of ROS, TNFa and NADPH oxidase subunits mRNA and protein in the PVN of rats with $\mathrm{OH}$ were significantly reversed by pentoxifylline (PTX, $30 \mathrm{mg} / \mathrm{kg}$ daily ip; in 10\% ethanol) application, a cytokine blocker, for a period of 5 weeks. PTX administration also significantly decreased SBP, AAR and plasma NE levels in rats with $\mathrm{OH}$.

Conclusions: TNFa in the PVN modulates AAR and contributes to sympathoexcitation in $\mathrm{OH}$ possibly through NADPH oxidase-dependent ROS generation. TNFa blockade attenuates AAR and sympathoexcitation that unveils TNFa in the PVN may be a possible therapeutic target for the intervention of $\mathrm{OH}$.

Keywords: Adipose afferent reflex, TNFa, Paraventricular nucleus, Sympathoexcitation, Obesity, Reactive oxygen species

\footnotetext{
*Correspondence: zhouyebo666@njmu.edu.cn

1 Department of Physiology, Nanjing Medical University, 101 Longmian

Road, Nanjing 211166, China

Full list of author information is available at the end of the article
} 


\section{Background}

Worldwide prevalence of obesity has rapidly increased, especially in younger population in recent years and become a major threat to people's health $[1,2]$. Chronic sympathetic overactivation is a hallmark of obesity and contributes to the development of cardiovascular diseases including hypertension and heart failure [3-5]. Moreover, central mediation plays an important role in the enhancement of sympathoexcitation in obesity [6-8].

Recent studies on abnormality of sympathetic nerve activity (SNA) in obesity has targeted the hypothalamus and illustrated that hypothalamic paraventricular nuclei (PVN), an important central site for the integration of SNA and the regulation of cardiovascular function, can mediate obesity pathogenesis [9-12]. The increased abdominal visceral fat composed of white adipose tissue (WAT) is a very important contributing factor for the sympathetic overdrive and hypertension [13]. Neuroanatomical and functional studies indicate the existence of sensory and sympathetic innervations in the WAT $[14,15]$. The adipose afferent reflex (AAR), a sympathoexcitatory reflex for increasing SNA and blood pressure (BP), can be induced by the stimulation of afferent nerve fibres of WAT with capsaicin (CAP) [13]. A related study from our laboratory demonstrated PVN mediated the enhanced AAR implicates the pathogenesis of obesityrelated hypertension $(\mathrm{OH})[16]$.

Increasing evidence show that inflammation is involved in the progression of many diseases, and it is a common feature both in obesity [17] and hypertension [18]. Elevated proinflammatory cytokines (PICs) are transported into the PVN primarily via the circumventricular organs [19], and the accumulated PICs such as tumor necrosis factor $\alpha(\mathrm{TNF} \alpha)$ in the PVN can regulate SNA and cardiovascular function in rats with hypertension or chronic heart failure (CHF) [20-22]. Moreover, the elevated PICs in the PVN induce the production of reactive oxygen species (ROS) which are cytotoxic, further contributing to sympathoexcitatory effects [23-26]. However, the increase of ROS induced by TNF $\alpha$ for the modulation of AAR and SNA in the PVN in $\mathrm{OH}$ is unexplored. Some studies also showed that the rats with $\mathrm{CHF}$ or hypertension had an increased level of TNF $\alpha$ or ROS in the PVN, resulting in the sympathoexcitation [21, 22]. TNF $\alpha$ as a contributor to oxidative stress, either directly or indirectly plays an important role in the progression of obesity [27]. TNF $\alpha$ modulates the activity and protein expression of NADPH oxidase, a potential source of ROS, involving the progress of cardiovascular diseases $[21,22]$. However, the pathophysiological significance of the increased levels of TNF $\alpha$ within the PVN modulating AAR and sympathetic outflow in $\mathrm{OH}$ remains obscure. Therefore, the present study was designed to verify the hypothesis that TNF $\alpha$ may modulate NADPH oxidasedependent ROS generation in the PVN involving the enhancement of AAR and SNA in rats with $\mathrm{OH}$.

\section{Materials and methods}

Adult male Sprague-Dawley rats weighing 300-350 g were used for the induction of $\mathrm{OH}$ rats by using high-fat diet (HFD, $45 \% \mathrm{kcal}$ as fat: $45 \%$ fat, $40 \%$ carbohydrate, and $15 \%$ protein. TROPHIC Animal Feed High-tech Co Ltd, Nantong, China) for 12 weeks in this study. They were housed in a temperature and light-controlled room and provided with water and chow ad libitum. After 12 weeks, rats consuming the HFD were ranked based on weight gain and BP. The rats with more weight gains and $\mathrm{BP} \geq 140 \mathrm{mmHg}$ were referred to as $\mathrm{OH}$ group, and the rats with control diet $(12 \% \mathrm{kcal}$ as fat: $12 \%$ fat, $60 \%$ carbohydrate and $28 \%$ protein. TROPHIC Animal Feed High-tech Co Ltd, Nantong, China) were used as Control group. The experimental procedures were in compliance with the Guide for the Care and Use of Laboratory Animals (NIH publication, 8th edition, 2011) and approved by the Experimental Animal Care and Use Committee of Nanjing Medical University. The rats with $\mathrm{OH}$ were subsequently injected with PTX $(30 \mathrm{mg} / \mathrm{kg}$ daily ip; in $10 \%$ ethanol) or vehicle ( $10 \%$ ethanol alone) for 5 weeks. Rats were killed under anesthesia with an overdose of sodium pentobarbital by intraperitoneal injection, and the plasma and PVN tissues were collected for further analysis.

\section{Measurement of body weight (BW) and systolic blood pressure (SBP)}

The BW and SBP of rats were measured in a conscious state. SBP of tail artery was detected by using a noninvasive computerized tail-cuff system (NIBP, AD Instruments, Sydney, Australia). The rat was warmed for about $20 \mathrm{~min}$ to detect the pulsation of tail artery and obtain a steady pulse level. Moreover, in order to minimize the SBP fluctuation, the rat was trained for SBP measurement at least 10 days before the experiment formally started. This experiment was repeated 10 times in a rat, and SBP value was the mean of ten replicates.

\section{General procedures of acute experiment}

Acute experiment was carried out after 12 or 17 weeks, the rats underwent anesthesia with urethane $(800 \mathrm{mg} /$ $\mathrm{kg}$, ip) and $\alpha$-chloralose (40 mg/kg, ip). Midline incisions were made for exposing the trachea and the right carotid artery, then the trachea was cannulated and connected with a rodent ventilator (Model 683, Harvard Apparatus Inc, USA), and the carotid artery was cannulated and connected with pressure transducer for recording of mean arterial pressure (MAP). A PowerLab data acquisition system (8/35, AD Instruments, Sydney, Australia) 
was used for simultaneous recording of the renal sympathetic nerve activity (RSNA) and MAP.

\section{RSNA recording}

The dynamic alterations of sympathetic outflow was assessed by recording RSNA continuously. Simply, the retroperitoneal incision was made for the isolation of left renal sympathetic nerve which was cut distally to eliminate its afferent activity, then the nerve was placed on a pair of silver electrodes. An AC/DC differential amplifier (Model 3000; A-M System, Washington, DC, USA) was used to amplify the RSNA which was filtered with a band-pass between 10 and $3000 \mathrm{~Hz}$, and the signals were integrated at a constant of $100 \mathrm{~ms}$. At the end of experiment, the baseline noise was measured after section of the central end of the nerve, then subtracted from the integrated RSNA data. The RSNA change (in \%) was the percent change from baseline RSNA value which were determined by averaging 2 min of its maximal responses after a certain chemical microinjection into the PVN. AAR was evaluated by averaging 2 min of the maximal RSNA and MAP responses to CAP within the time range from 10 to $30 \mathrm{~min}$ after the application of CAP, and the RSNA change (in \%) was the percent change from values before CAP.

\section{AAR induction and evaluation}

CAP, a common and valuable tool for exploring the function of sensory afferent fibres, was used to stimulate the sensory afferent fibres in right inguinal WAT (iWAT) for the induction of AAR. Briefly, the right iWAT area was exposed by an inguinal incision, and four thin and sharp stainless steel tubes $(0.31 \mathrm{~mm}$ outer diameter) were inserted into iWAT ( $3 \mathrm{~mm}$ ) under the surface of fat pads. The tips of these tubes were spaced $(4 \mathrm{~mm})$ apart from each other and connected with a 4-channel programmable pressure injector (PM2000B; MicroData Instrument, Plainfield, NJ, USA). CAP $(1.0 \mathrm{nmol} / \mu \mathrm{L})$ was injected into the right iWAT at a rate of $4.0 \mu \mathrm{L} / \mathrm{min}$ for $2 \mathrm{~min}$ for each site. The RSNA and MAP responses to injection of CAP were used to evaluate the AAR. At the end of experiment, Evans blue $(8 \mu \mathrm{L})$ was injected into the iWAT for histological identification of WAT, and the diffusion diameter of blue dye localized in iWAT was less than $3 \mathrm{~mm}$ in all rats.

\section{PVN microinjection}

Stereotaxic coordinates for PVN were $1.8 \mathrm{~mm}$ caudal from bregma, $0.4 \mathrm{~mm}$ lateral to midline and $7.9 \mathrm{~mm}$ ventral to dorsal surface referred to the atlas of the rat brain. To locate the PVN, the rat was fixed in a stereotaxic frame (Chicago, USA), then microinjection volume of $50 \mathrm{~nL}$ for each side of PVN was applied by two glass micropipettes (50 $\mu \mathrm{m}$ tip diameter). The bilateral microinjections of chemicals were finished within $1 \mathrm{~min}$. At the end of the experiment, same volume of Evans Blue was injected into the microinjection sites for histological identification of PVN. A representative picture of microinjection sites in the PVN evaluated by Evans blue diffusion was shown in Fig. 1. The data would be excluded from data analysis if microinjection sites were outside the PVN. Total 3 rats in different groups were excluded from data analysis because the microinjection sites were not within the PVN.

\section{Blood and PVN samples preparation}

Each rat was anaesthetized with an overdose of sodium pentobarbital by intraperitoneal injection. For better anesthetic effect, $2 \%$ sodium pentobarbital solution was prepared before operation. The rats were anesthetized with the normal dose according to the weight $(0.3 \mathrm{~mL} / 100 \mathrm{~g})$. If the animals were not completely anesthetized, we increased the dose about a fifth of the total amount. At this dose, most animals can be completely anesthetized. In general, the anesthesia duration from the beginning to the end is within a few minutes, which generally does not affect the protein expression in the brain. But the protein phosphorylation may be affect by overdose application of sodium pentobarbital, and this needs to be further explored. Blood were collected in heparinized tubes. Plasma samples obtained by centrifugation of heparinized blood for $15 \mathrm{~min}$ were used for the estimation of circulating norepinephrine (NE) and TNF $\alpha$ levels. The brain was quickly removed and frozen with liquid nitrogen. Finally, the plasma and brain were stored at $-80{ }^{\circ} \mathrm{C}$ until being used. Coronal sections of the brain were obtained with a cryostat microtome (Leica CM1900-1-1, Wetzlar, Hessen, Germany) at the PVN level.

\section{Measurement of plasma glucose, insulin, cholesterol and triglyceride levels}

About $1.5 \mathrm{~mL}$ of blood was collected from tail vein. Fasting glucose [using glucose oxidase method and kit from Jiancheng Bioengineering (Nanjing, China)], fasting insulin [using enzyme-linked immunoassay (Elisa) method and kit from RayBiotech, Inc. (Norcross, GA, USA)], cholesterol and triglyceride [using commercial colorimetric assay and kits from Jiancheng Bioengineering (Nanjing, China)] levels in the plasma were measured in Control and $\mathrm{OH}$ groups according to the manufacturer's instructions.

\section{Measurement of plasma NE and TNFa levels}

The levels of NE and TNF $\alpha$ were measured using Elisa method by using kits, and the manufacturer's instructions 

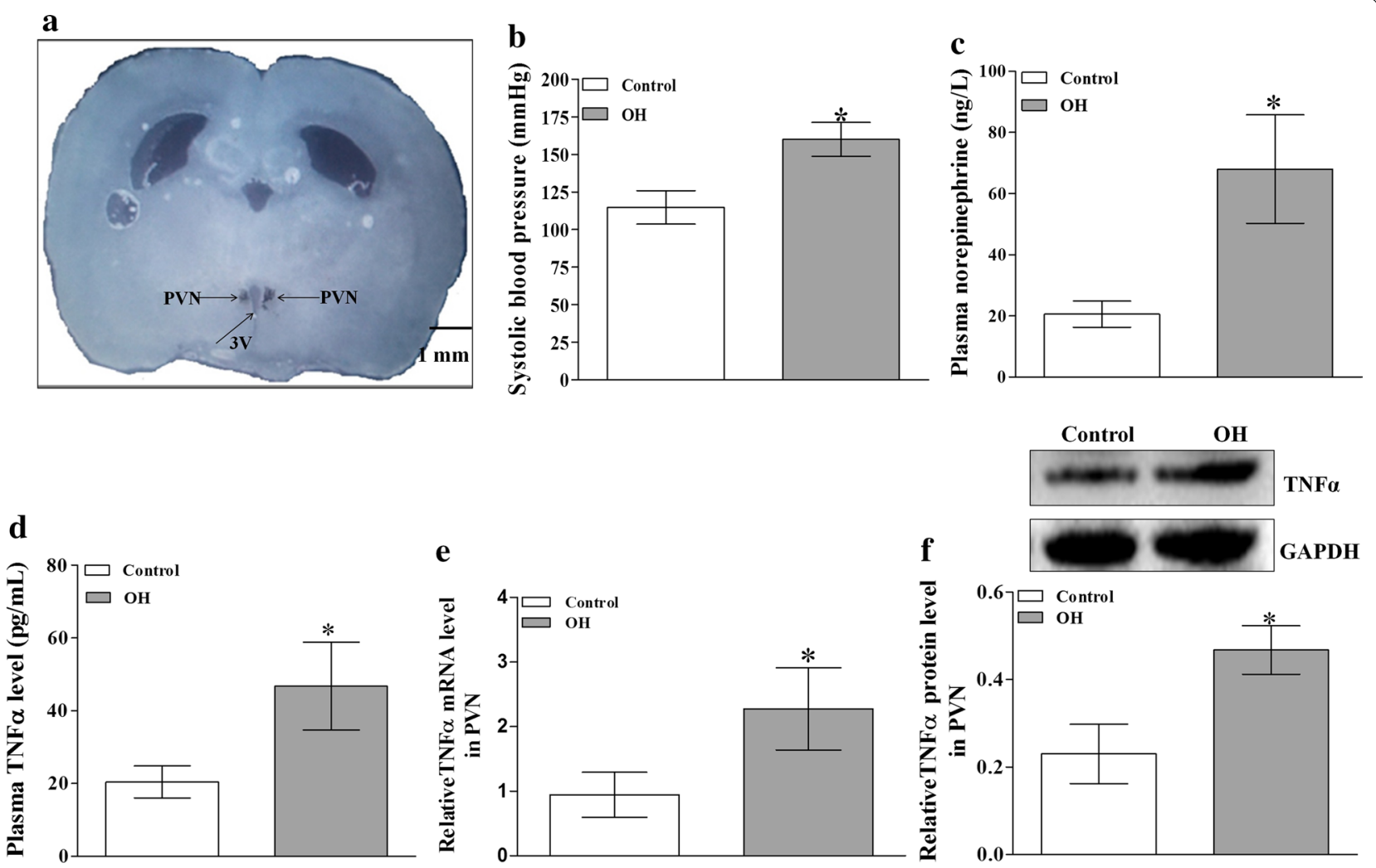

Fig. 1 A representative picture of microinjection sites in the PVN evaluated by Evans blue ( $50 \mathrm{~nL})$ diffusion (a); the effect of HFD on the values of systolic blood pressure (SBP) and the plasma levels of norepinephrine (NE) and TNFa ( $\mathbf{b}-\mathbf{d}$ for each group, $n=7$ ); and the relative values of TNFa protein expression and mRNA levels in the PVN (e, $\mathbf{f}$ for each group, $n=4-5)$. The values are mean $\pm S D . * p<0.05$ versus Control. Arrows indicate the microinjection sites. PVN paraventricular nucleus, $3 \mathrm{~V}$ the third ventricle, $\mathrm{OH}$ obesity-related hypertension. SBP was measured under conscious state

were followed. The final solution was read by a microplate reader (ELX800, BioTek, Vermont, USA). The kits for detecting NE and TNF $\alpha$ levels were from R\&D systems (Minneapolis, MN, USA).

\section{Examination of ROS in the PVN}

In situ ROS in the PVN were examined using dihydroethidium (DHE) staining. PVN region was achieved from the coronally sectioned $(30 \mu \mathrm{m})$ brain tissues of rats and it was placed onto chilled slides. The sections were thawed and rehydrated using phosphate-buffered saline, then incubated with DHE $(1 \mu \mathrm{M})$ in the dark. DHE fluorescence was viewed and imaged under confocal microscopy (Zeiss LSM 510). Moreover, we also detected the content of ROS in the PVN by using the lucigenin-derived chemiluminescence method. Dark-adapted lucigenin can react with ROS causing photon emission which is detected by a luminometer (20/20n, Turner, CA, USA) once every minute for $10 \mathrm{~min}$. The data representing the ROS content is expressed as the MLU per minute per milligram of protein.

\section{Measurement of NADPH oxidase activity}

The activity of PVN NADPH oxidase was determined by the enhanced lucigenin chemiluminescence method [25]. Briefly, NADPH $(100 \mu \mathrm{M})$ used as a substrate, reacts with NADPH oxidase in the medium to generate ROS which can react with lucigenin $(5 \mu \mathrm{M})$ to produce light emission. A luminometer (20/20n, Turner, CA, USA) was used to detect the light emission once every minute for $10 \mathrm{~min}$. The data representing the NADPH oxidase activity were expressed as the (MLU) per minute per milligram of protein.

\section{Measurement of TNFa, NOX2 and NOX4 protein expressions}

The protein expressions of TNF $\alpha$, NOX2 and NOX4 in the PVN were measured as previously reported [26]. Simply, the total PVN protein in the homogenate was extracted and measured. Western blot analysis was carried out by using the rabbit polyclonal antibodies of TNF $\alpha$ (Cell Signaling Technology, Danvers, MA, USA), NOX2, NOX4 (Abcam, Burlingame, CA, USA) and GAPDH (Bioworld 
Technology, Louis Park, MN, USA) as the primary antibodies. Peroxidase-conjugated goat anti-rabbit secondary antibody (Santa Cruz, CA, USA) was used as secondary antibody. The levels of TNF $\alpha$, NOX2 and NOX4 protein expression were expressed as the ratio to GAPDH protein, respectively.

\section{RNA isolation and real-time RT-PCR}

The total RNA was extracted from the microdissected PVN by using Tri-Zol reagent (Invitrogen) and reverse transcribed with oligo (dT) and RT. GAPDH was used as housekeeping gene. Real-time RT-PCR was performed in 96-well PCR plates using Bio-Rad PCR Master Mix (the iTaq SYBR Green Supermix with ROX) and the ABI Prism 7900 sequence detection system (Applied Biosystems). The expression levels of TNF $\alpha$, NOX2 and NOX4 were determined using specific rat primers (TNF $\alpha$ : Forward primer: 5'-CCTTATCTACTCCCAGGTTCTC-3'; Reverse primer: 5'-TTTCTCCTGGTATGAATGGC-3'; NOX2: Forward primer: 5'-CTGCCAGTGTGTCGGAATCT-3', Reverse primer: AATGGCCGTGTGAAGTGCTA-3'; NOX4: Forward primer: 5'-TGGCCAACGAAGGGGTTAAA-3', Reverse primer: 5'-CACTGAGAAGTTCAGGGCGT-3'). The values were corrected by GAPDH (Forward primer: 5'-TGATGGGTGTGAACCACGAG-3', Reverse primer: CCCATAACCCCCACAACACT) and were calculated using the formula $x=2^{-(\Delta \Delta \mathrm{Ct})}[28]$.

\section{Chemicals}

Capsaicin (CAP), PEG-SOD, NADPH $(100 \mu \mathrm{M})$, lucigenin $(5 \mu \mathrm{M})$, diethyldithiocarbamate (DETC), Apo, TNF $\alpha$, R-7050 $(10 \mu \mathrm{M})$ and pentoxifylline (PTX) were obtained from Sigma Chemical (St. Louis, MO, USA). The doses of CAP (1 nM), PEG-SOD (5 units), DETC (10 nM), Apo $(1 \mathrm{nM}), \mathrm{TNF} \alpha(1 \mathrm{ng})$ and PTX $(30 \mathrm{mg} / \mathrm{kg}$ daily ip; in $10 \%$ ethanol) were chosen with reference to our preliminary studies and published papers $[22,25,26]$.

\section{Statistical analysis of data}

All data illustrated are expressed as mean \pm SD. GraphPad Prism v5.00 (GraphPad Software, CA) was used for statistical analyses. Differences in the mean values between two groups were assessed by two-tailed Student $t$-test. One-way and two-way ANOVA were used for data analysis of more than two groups followed by Bonferroni's post hoc analysis. In all cases, $\mathrm{p}<0.05$ was considered statistically significant.

\section{Results}

\section{The effects of HFD consumption on metabolic} and anatomic data

After 12 weeks of HFD consumption, plasma insulin, cholesterol, and triglyceride levels, as well as heart weight, body weight and white adipose tissue (WAT) mass were significantly increased in rats with $\mathrm{OH}$ (Table 1). The SBP, TNF $\alpha$ and NE (it is often used to evaluate basal SNA) levels in the plasma of rats with $\mathrm{OH}$ were much higher than in the Control rats (Fig. 1). These results were almost in line with our previous published results [25]. HFD consumption promoted the increase of plasma TNFa level which may be associated with the enhanced SNA.

\section{HFD consumption promoted the expressions of TNFa mRNA and protein in the PVN}

It was reported that TNF $\alpha$ in the PVN contributes to the sympathetic activation [20]. To investigate whether TNF $\alpha$ in the PVN is involved in sympathetic activation and hypertension in $\mathrm{OH}$, we firstly examined the mRNA and protein expressions of TNF $\alpha$. When compared with the control group, the significant increases of TNF $\alpha$ mRNA (Fig. 1e) and protein levels (Fig. 1f) were found in the PVN of rats with $\mathrm{OH}$. These changes may alter the excitability of neurons in the PVN for enhancing the sympathetic activation.

\section{PVN microinjection of TNFa enhanced the basal SNA}

The effects of TNF $\alpha$ in the PVN on sympathetic outflow and $\mathrm{BP}$ in $\mathrm{OH}$ remains unclear, here we investigated the roles of PVN administration of TNFa in RSNA and MAP. Stable baseline values of RSNA and MAP were recorded for 10-15 $\mathrm{min}$, then the saline and TNF $\alpha$ were injected into the PVN, respectively, and the recording was recorded for $90 \mathrm{~min}$. The maximal values of baseline RSNA and MAP were evaluated for 2 min from 30 to $40 \mathrm{~min}$ after saline or TNF $\alpha$ microinjection. The peak of the pressor and sympathoexcitory responses due to the microinjection of TNF $\alpha$ into the PVN occured around 15-45 min after the injection, so AAR induction was started $15 \mathrm{~min}$ after TNF $\alpha$ infusion. The duration of

Table 1 Metabolic parameters and anatomic data in control and $\mathrm{OH}$ rats after 12 weeks of diet

\begin{tabular}{lll}
\hline Parameters & Control & OH \\
\hline BW $(\mathrm{g})$ & $513 \pm 41$ & $627 \pm 45^{*}$ \\
Plasma glucose $(\mathrm{mg} / \mathrm{dl})$ & $132 \pm 11$ & $143 \pm 14$ \\
Plasma insulin $(\mathrm{ng} / \mathrm{ml})$ & $1.61 \pm 0.18$ & $2.92 \pm 0.29^{*}$ \\
Plasma cholesterol $(\mathrm{mg} / \mathrm{dl})$ & $40.2 \pm 4.1$ & $58.9 \pm 5.7^{*}$ \\
Plasma triglyceride $(\mathrm{mg} / \mathrm{dl})$ & $62.7 \pm 5.9$ & $88.7 \pm 8.1^{*}$ \\
HW (mg) & $1573 \pm 92$ & $2148 \pm 116^{*}$ \\
HW/BW (mg/g) & $3.07 \pm 0.31$ & $3.43 \pm 0.42$ \\
Sum of WAT mass (g) & $27.5 \pm 3.1$ & $56.2 \pm 4.8^{*}$ \\
\hline
\end{tabular}

Sum of WAT mass includes inguinal, retroperitoneal, epididymal and mesenteric WAT mass. Values are mean \pm SEM. $n=10$ for each group

$\mathrm{OH}$ obesity-related hypertensive rats induced by high fat diet, $\mathrm{BW}$ body weight, $H W$ heart weight, WAT white adipose tissue

${ }^{*} \mathrm{p}<0.05$ versus Control 
TNFo's action in the PVN was around 50-60 min. Acute microinjection of TNF $\alpha(1 \mathrm{ng} / 50 \mathrm{~nL})$ into the bilateral PVN significantly increased basal SNA in the two groups compared with PVN microinjection of saline $(\mathrm{p}<0.05$ for all comparisons) (Fig. 2a, b), which was significantly inhibited by PVN pretreatment of TNF $\alpha$ receptor antagonist R-7050 (Fig. 2c, d). These results suggested that TNF $\alpha$ via receptor pathway participates in the modulation of SNA.

\section{TNFa in the PVN strengthened the AAR in rats with $\mathrm{OH}$}

The enhanced AAR contributes to sympathetic activation in diet-induced obese rats or obesity-related hypertensive rats [13]. In this study, the AAR was evaluated by the RSNA and MAP responses to capsaicin (CAP) injection into the right iWAT. CAP is a valuable chemical reagent for studying the function of sensory afferent fibers, and the AAR is induced by CAP $(1.0 \mathrm{nM})$ injection into four sites of the right iWAT at a rate of $4.0 \mu \mathrm{L} / \mathrm{min}$ for $2 \mathrm{~min}$. The AAR was markedly enhanced and TNF $\alpha(1 \mathrm{ng} / 50 \mathrm{~nL})$ injected into PVN significantly increased the AAR in rats with $\mathrm{OH}$ when compared with the control rats $(\mathrm{p}<0.05$,
Fig. 3c, d), which indicated that TNF $\alpha$ in the PVN may strengthen the AAR to affect SNA in $\mathrm{OH}$. The representative recordings of the enhancement of AAR caused by TNFo were shown in Fig. 3a, b.

\section{Pretreatment of R-7050, PEG-SOD or Apo in the PVN inhibited, but DETC augmented the AAR caused by TNFa} In order to determine whether ROS derived from NADPH oxidase are involved in TNF $\alpha$-induced enhancement of AAR, we used the ROS scavenger PEG-SOD, a NADPH oxidase inhibitor apocinin (Apo) and a superoxide dismutase inhibitor DETC, respectively, to investigate their effects on the enhanced AAR-induced by TNF $\alpha$ in the PVN. We found that the pretreatment of R-7050, PEG-SOD or Apo in the PVN significantly inhibited the AAR enhancement caused by TNF $\alpha$ in rats with $\mathrm{OH}$, but pretreatment of DETC further strengthened the AAR compared to the single TNF $\alpha$ injection $(\mathrm{p}<0.05$ for each, Fig. 4a-d). We previously reported that ROS derived from NADPH oxidase in the PVN are involved in the sympathetic activation and hypertension [25]. The results in this study suggested that TNF $\alpha$ via receptor pathway
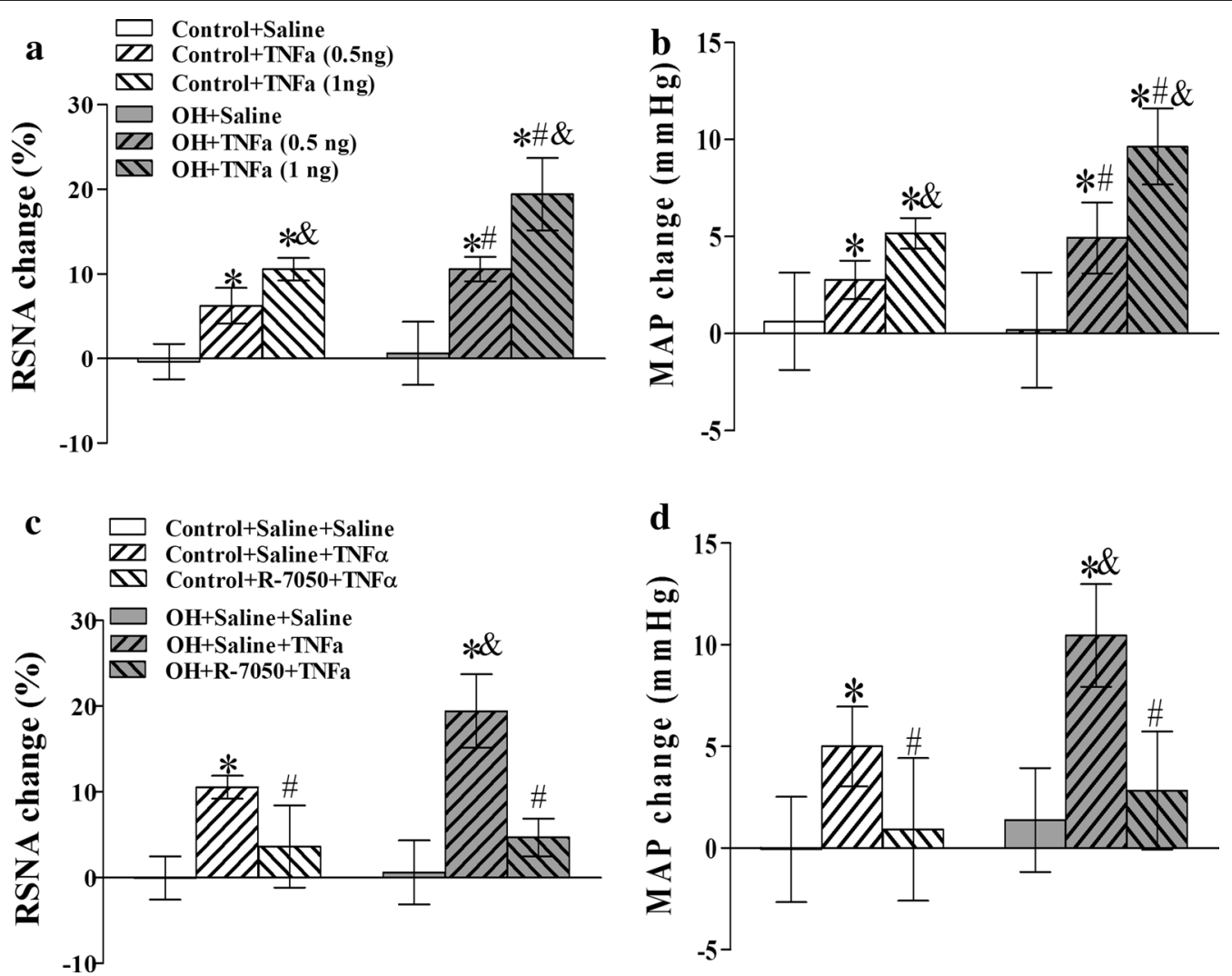

Fig. 2 The effects of PVN microinjection of saline and TNFa (0.5 ng or $1 \mathrm{ng})$ on the baseline RSNA and MAP (a, b), and TNFa (1 ng) caused SNA response (the changes of RSNA and MAP) to the pretreatment of TNFa receptor antagonist R-7050 in the PVN. The values are mean \pm SD. For each group, $\mathrm{n}=6-7 ;{ }^{*} \mathrm{p}<0.05$ versus saline $(\mathbf{a}, \mathbf{b}) ;{ }^{*} \mathrm{p}<0.05$ versus Control $(\mathbf{a}, \mathbf{b}) ;{ }^{*} \mathrm{p}<0.05$ versus TNFa $(0.5 \mathrm{ng} \mathbf{a}, \mathbf{b}) ;{ }^{*} \mathrm{p}<0.05$ versus Saline + Saline $(\mathbf{c}, \mathbf{d})$; ${ }^{\&} p<0.05$ versus Control $(\mathbf{c}, \mathbf{d}) ; \# p<0.05$ versus Saline + TNFa $(\mathbf{c}, \mathbf{d})$. RSNA renal sympathetic nerve activity, MAP mean artery pressure 


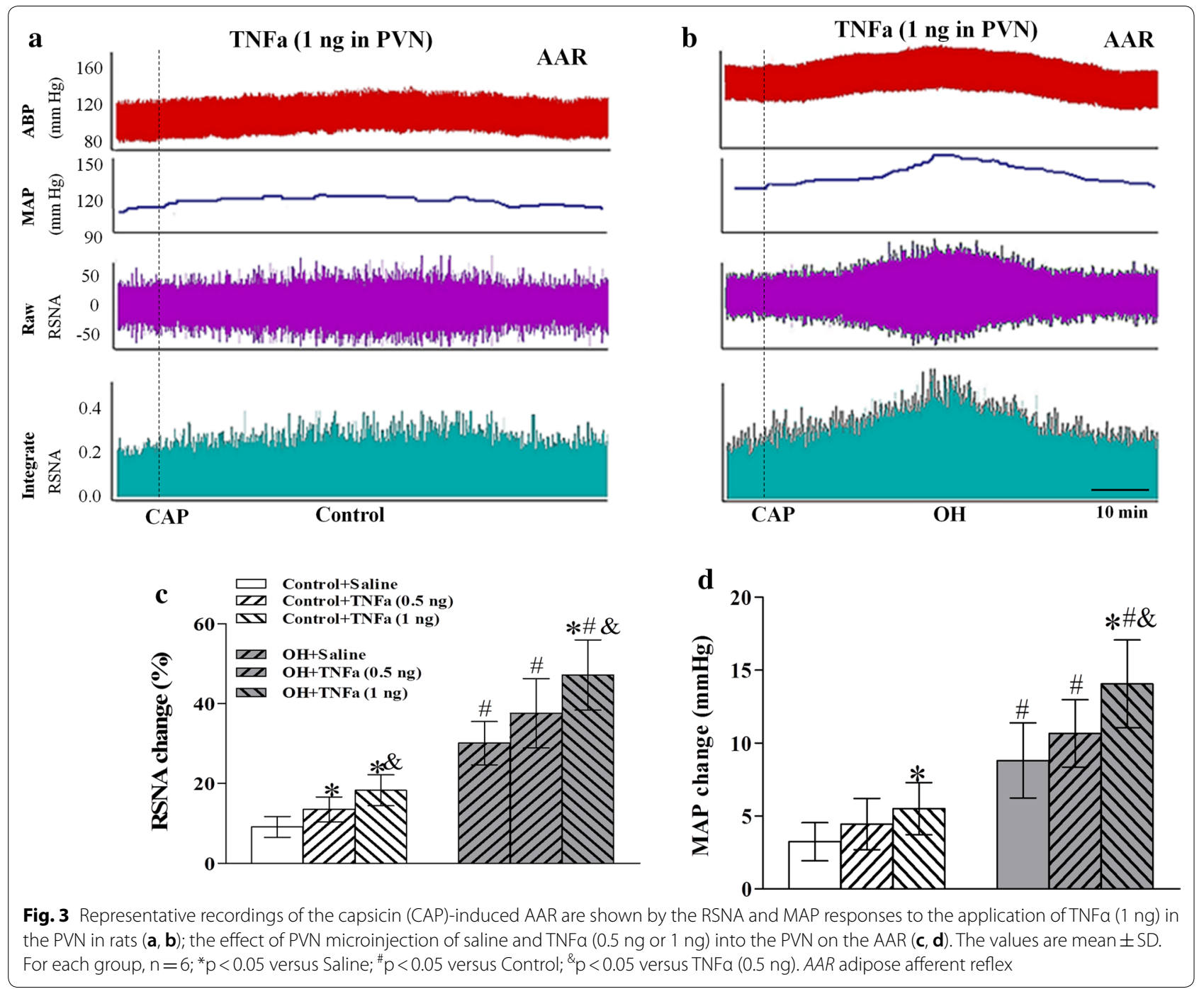

may stimulate the NADPH oxidase activity to increase the production of ROS for promoting the AAR enhancement in $\mathrm{OH}$.

\section{Pretreatment of R-7050 in the PVN reduced the ROS level} and NADPH oxidase activity caused by TNFa

For further illustrating TNF $\alpha$ via receptor pathway to stimulate the NADPH oxidase activity and the ROS production, we microinjected TNF $\alpha$ or R-7050 into PVN to determine the NADPH oxidase activity and ROS level. Compared with the microinjection of saline into the PVN, TNF $\alpha$ in the PVN caused significant increases in the ROS level and NADPH oxidase activity in rats with $\mathrm{OH}$, but the pretreatment of R-7050 significantly inhibited the effects of TNF $\alpha$ on them $(p<0.05$ for each, Fig. 5e, f). In situ detection of PVN ROS by the dihydroethidium (DHE) method (a superoxide-sensitive dye staining technique) revealed a much higher fluorescent intensity in rats with $\mathrm{OH}$ compared with control rats (Fig. 5a-d). These findings verified our hypothesis that TNF $\alpha$ via receptor pathway can stimulate the increases of NADPH oxidase activity and ROS production.

\section{Chronic pentoxifylline (PTX) treatment on metabolic and anatomic data in rats}

After HFD consumption for 12 weeks, PTX (a cytokine blocker, $30 \mathrm{mg} / \mathrm{kg}$, IP) was administrated. The rats with $\mathrm{OH}$ continued to be fed HFD for 5 weeks. The results showed that PTX decreased the plasma insulin level when compared with the $\mathrm{OH}$ group (Table 2). Although the PTX treatment had a tendency to decrease the heart weight, body weight, and white adipose tissue mass, their changes were not significant (Table 2). The mechanism for PTX decreasing the level of plasma insulin in rats with $\mathrm{OH}$ deserves further exploration. 

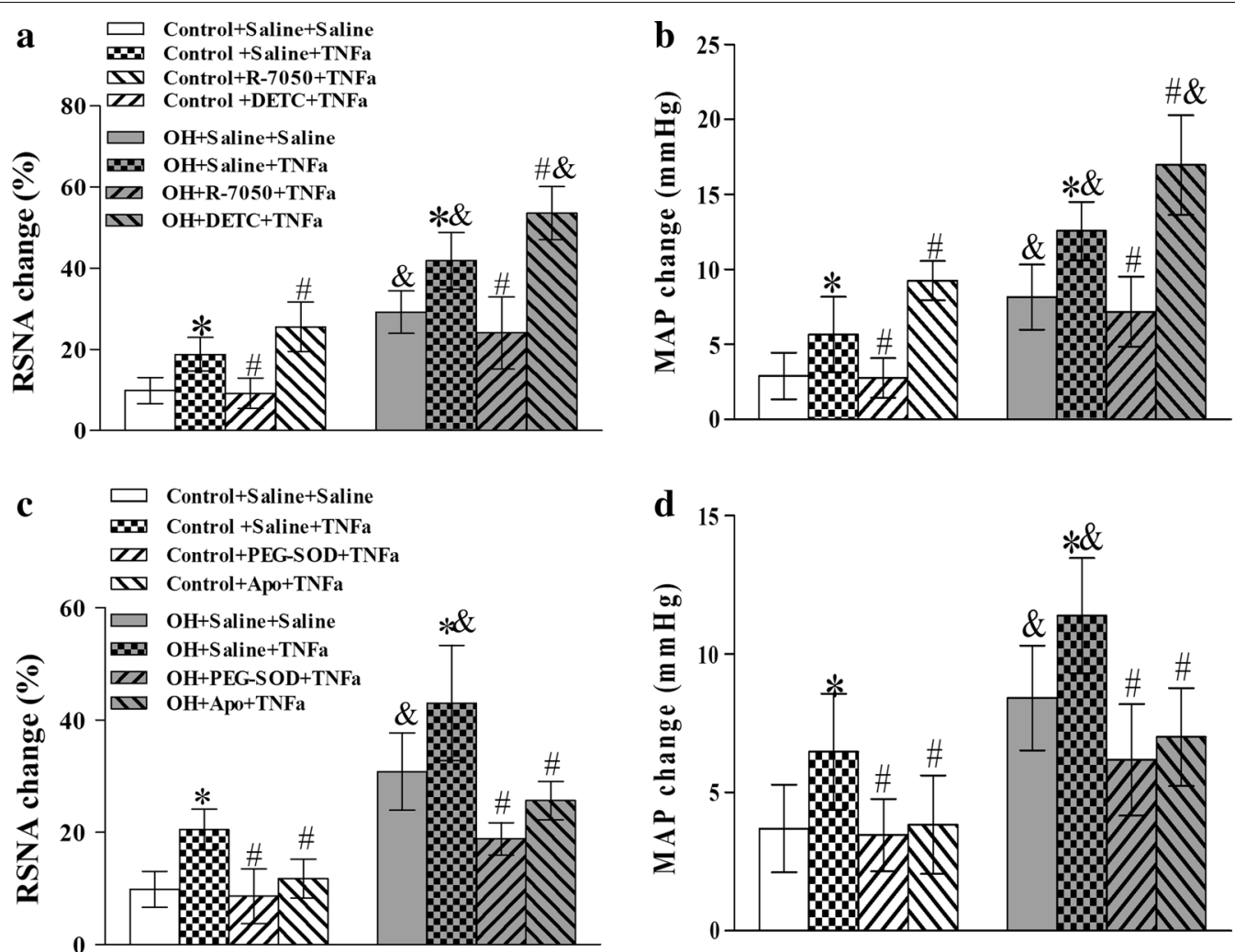

Fig. 4 The effects of saline, R-7050 (TNFa receptor antagonist), DETC (superoxide dismutase inhibitor), PEG-SOD (superoxide scavenger) and Apo (NADPH oxidase inhibitor) pretreatment in the PVN on the AAR response to TNFa in the PVN. TNFa (1 ng) was administered 10 min after the pretreatment. The values are mean \pm SD. For each group, $n=6-7 ;{ }^{*} p<0.05$ versus Saline + Saline; ${ }^{\#} p<0.05$ versus Saline + TNFa $(1 \mathrm{ng}) ;{ }^{\circledR} p<0.05$ versus Control

\section{Chronic PTX treatment decreased sympathetic activity, SBP and AAR}

The AAR, SBP and plasma NE levels were significantly increased in rats with $\mathrm{OH}$, which were significantly decreased by PTX treatment for 5 weeks $(p<0.05$ in all cases, Fig. 6a-d). However, the AAR, SBP and NE levels in the control rats treated with PTX were not different from those of control rats. So PTX may inhibit the generation of peripheric $T N F \alpha$, which further reduces the amount of PVN TNF $\alpha$ coming from periphery being the reason for decreasing the AAR and SNA in rats with $\mathrm{OH}$.

\section{Chronic PTX treatment lowered ROS and TNFa levels in the PVN, and TNFa level in the plasma}

At the end of 17 weeks, the protein expression of TNF- $\alpha$ and ROS levels in the PVN, and the plasma TNF- $\alpha$ level were significantly increased in rats with $\mathrm{OH}$, which were significantly reduced by PTX chronic treatment. However, PTX in the normal rats had no significant effect on them $(\mathrm{p}<0.05$ in all cases, Fig. 7eg). In situ detection of ROS in the PVN illustrated a much stronger fluorescent intensity in rats with $\mathrm{OH}$ compared with the control rats (Fig. 7a-d), which was also obviously inhibited by PTX treatment. These findings indicated that the inhibition of cytokines generation can reduce ROS production in the PVN of rats with $\mathrm{OH}$.

\section{Chronic PTX treatment reduced the mRNA and protein expressions of NADPH oxidase isoforms (NOX2 and NOX4) in the PVN}

The levels of mRNA and protein expression of NADPH oxidase isoforms (NOX2 and NOX4) in the PVN were significantly upregulated in rats with $\mathrm{OH}$ when compared with the control rats. Similarly, the elevated mRNA and protein levels of NOX2 and NOX4 in the PVN were effectively inhibited in PTX-treated rats with $\mathrm{OH}(\mathrm{p}<0.05$ in all cases, Fig. $8 \mathrm{a}-\mathrm{d})$. The findings revealed that the inhibition of cytokines production suppressed the mRNA and protein expressions of NADPH oxidase isoforms (NOX2 and NOX4) in the PVN of rats with $\mathrm{OH}$. 


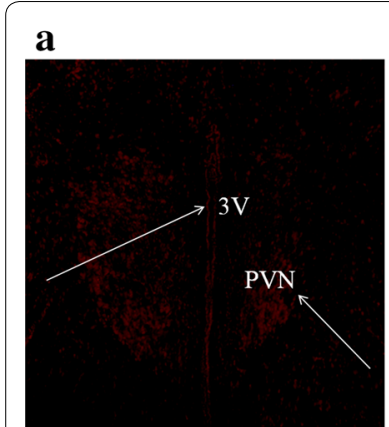

Control+Saline+Saline

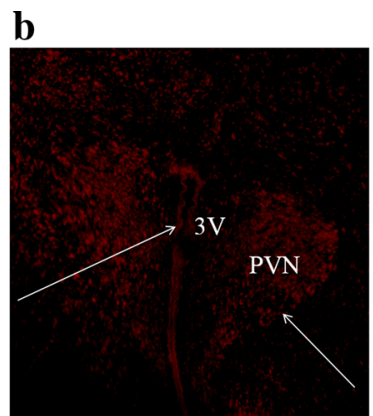

OH+Saline+Saline

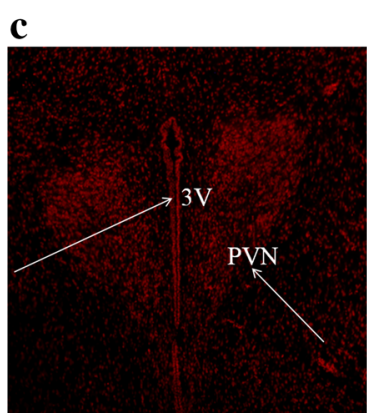

OH+Saline+TNFa

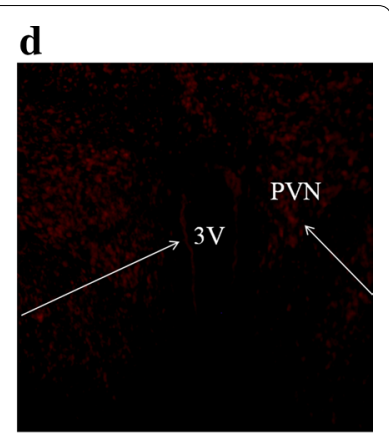

OH+R-7050+TNFa
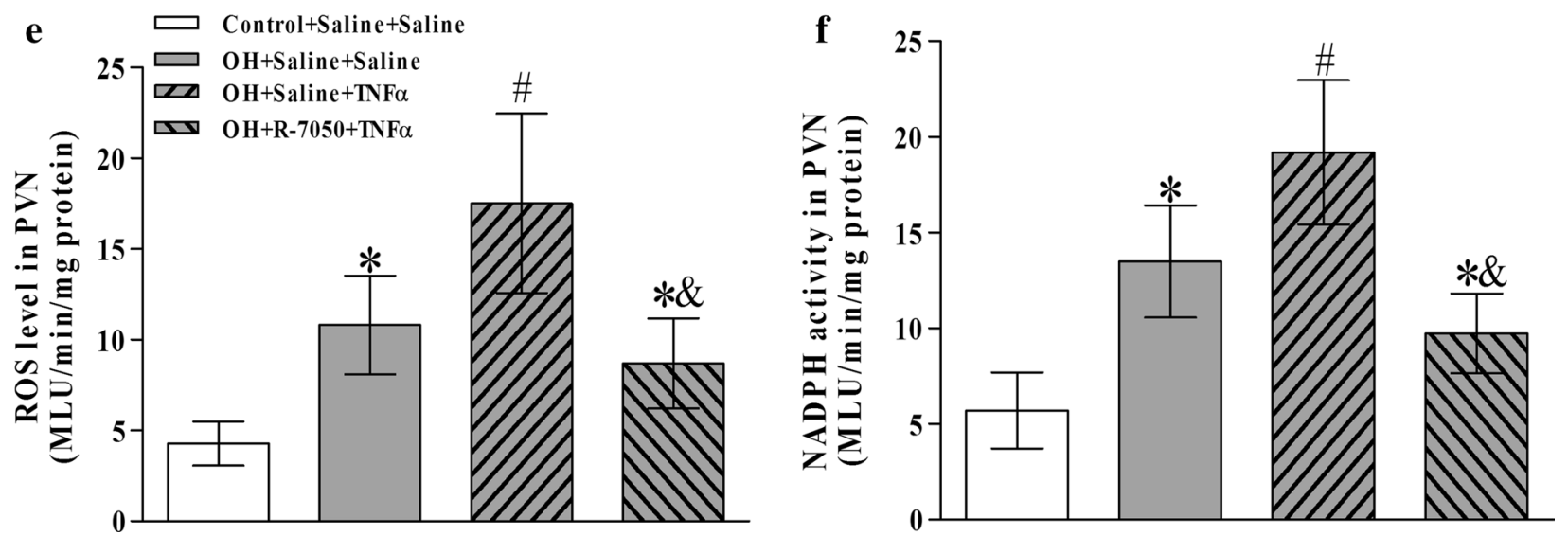

Fig. 5 The effects of R-7050 pretreatment on the NADPH oxiase activity (f), ROS level (e) and the in situ ROS content (a-d) responses to TNFa in the PVN. In situ ROS was determined with a specific fluorogenic probe by the DHE method ( $n=3$ for each group). The NADPH oxiase activity was detected by the enhanced lucigenin chemiluminescence method and the ROS level were measured by the lucigenin-derived chemiluminescence method ( $n=6$ for each group). The values are mean $\pm S D ;{ }^{*} p<0.05$ versus Control + Saline + Saline; $; p<0.05$ versus $\mathrm{OH}+$ Saline + Saline; ${ }^{\circledR} p<0.05$ versus $\mathrm{OH}+$ Saline + TNFa. $P V N$ paraventricular nucleus, $3 V$ the third ventricle

Table 2 Effects of pentoxifylline (PTX, a cytokine blocker, $30 \mathrm{mg} / \mathrm{kg}$, IP) treatment on metabolic and anatomic data in rats after HFD consumption for 17 weeks

\begin{tabular}{lllll}
\hline Parameters & Control & Control +PTX & OH & OH+PTX \\
\hline BW (g) & $559 \pm 41$ & $548 \pm 43$ & $688 \pm 51^{*}$ & $645 \pm 49$ \\
Plasma glucose (mg/dl) & $126 \pm 12$ & $122 \pm 11$ & $147 \pm 16$ & $142 \pm 15$ \\
Plasma insulin (ng/ml) & $1.51 \pm 0.3$ & $1.48 \pm 0.3$ & $3.12 \pm 0.31^{*}$ & $2.09 \pm 0.27^{\#}$ \\
Plasma cholesterol (mg/dl) & $43.1 \pm 4.1$ & $42.0 \pm 3.9$ & $61.2 \pm 6.5^{*}$ & $58.3 \pm 5.7$ \\
Plasma triglyceride (mg/dl) & $66.9 \pm 6.6$ & $65.8 \pm 7.2$ & $92.6 \pm 9.3^{*}$ & $85.2 \pm 7.9$ \\
HW (mg) & $1609 \pm 91$ & $1610 \pm 112$ & $2218 \pm 132^{*}$ & $3.22 \pm 0.37$ \\
HW/BW (mg/g) & $2.91 \pm 0.27$ & $2.94 \pm 0.35$ & $63.6 \pm 5.9^{*}$ & $3.13 \pm 0.40$ \\
Sum of WAT mass (g) & $28.5 \pm 3.1$ & $27.7 \pm 3.3$ & $57.9 \pm 4.2$ \\
\hline
\end{tabular}

Sum of WAT mass includes inguinal, retroperitoneal, epididymal and mesenteric WAT mass. Values are mean \pm SE. $n=10$ for each group

$\mathrm{OH}$ obesity-related hypertension rats induced by high fat diet, $B W$ body weight, $H W$ heart weight, WAT white adipose tissue

${ }^{*} \mathrm{p}<0.05$ versus Control; $\mathrm{*} p<0.05$ versus $\mathrm{OH}$

\section{Discussion}

The present study indicates HFD not only induced adiposity which was associated with an enhanced AAR and sympathoexcitation, as reflected by the increased plasma NE level and BP, but also caused an elevated concentration of circulating and PVN inflammatory cytokine 

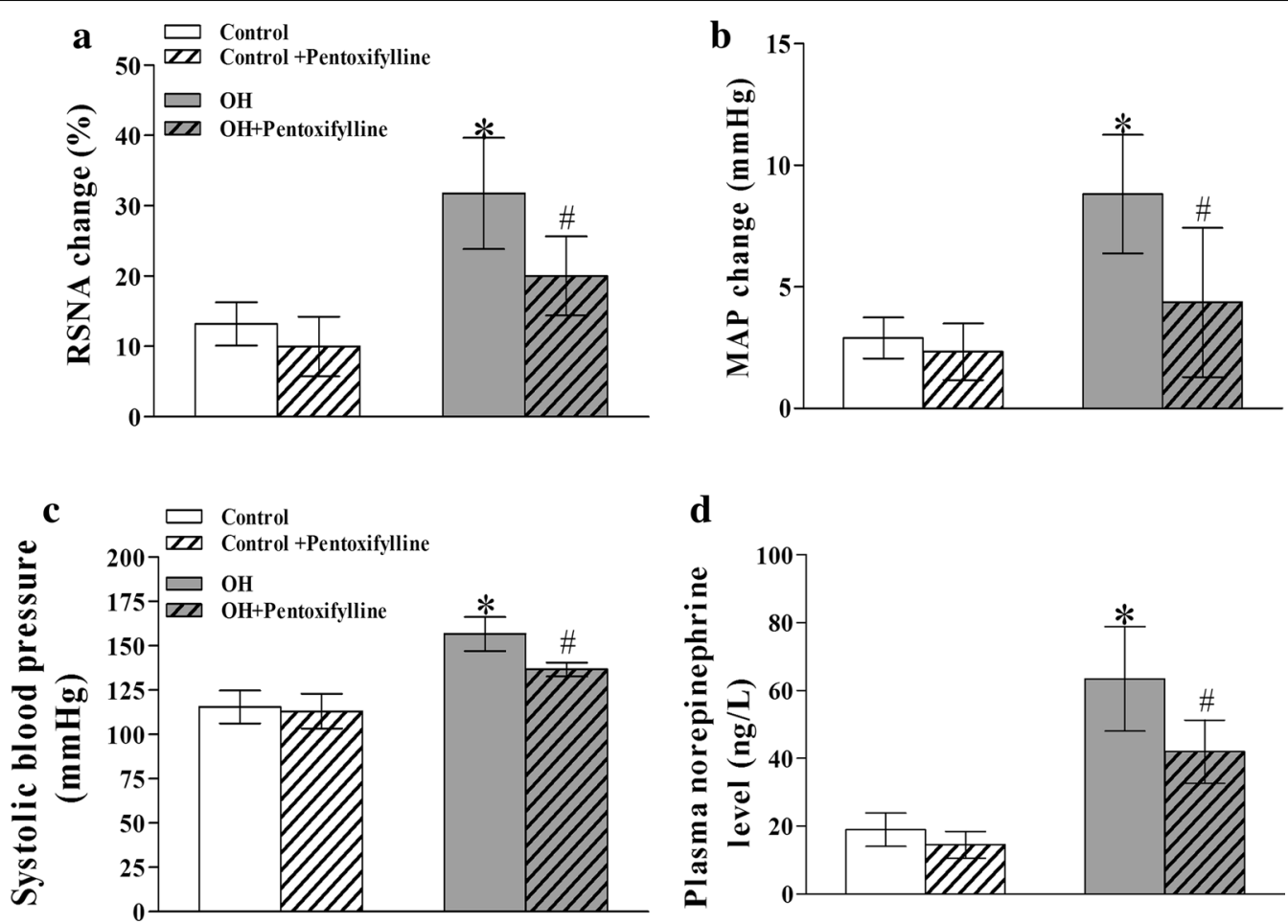

Fig. 6 The effects of chronic systemic application of pentoxifylline (PTX, a cytokine blocker, $30 \mathrm{mg} / \mathrm{kg}$, IP) for 5 weeks on the AAR (a, b), systolic blood pressure $(\mathbf{c})$ and plasma norepinephrine levels $(\mathbf{d})\left(n=6-7\right.$ for each group) in rats. Values are mean \pm SD. ${ }^{*} p<0.05$ versus Control; ${ }^{*} p<0.05$ versus $\mathrm{OH}$

TNF $\alpha$. Acute microinjection of TNF $\alpha$ into the PVN not only increased NADPH oxidase activity and ROS levels, but also caused significant increase in the AAR, which was inhibited by ROS scavenger PEG-SOD or NADPH oxidase inhibitor Apo in rats with $\mathrm{OH}$. Chronic systematic suppression of TNF $\alpha$ with PTX during the HFD period blunted TNF $\alpha$ production and attenuated the enhanced the AAR, SNA and hypertension in rats with $\mathrm{OH}$. PTX also decreased the mRNA and protein expressions of NADPH oxidase subunits and ROS level in the PVN of HFD-fed rats. Together, these findings suggested that chronic HFD consumption causes an increase of inflammatory cytokine TNF $\alpha$ in the PVN which appears to promote the increase of ROS, initiate the elevation of AAR, and further result in the elevation of SNA and BP.

Elevated TNFa levels in the PVN can evoke sympathoexcitation [24, 25]. TNF $\alpha$ blockade attenuated NE levels in the hypothalamus, suggesting a major intermediary role for TNFa in sympathoexcitation [21]. In this study, HFD induced the increases in TNF $\alpha$ protein and mRNA levels in the PVN. Acute microinjection of TNF $\alpha$ into the PVN caused the significant increases in the AAR, SNA and BP, which was inhibited by TNF $\alpha$ receptor antagonist used in the PVN of rats with $\mathrm{OH}$. This suggests that the increased TNF $\alpha$ level in the PVN of rats with $\mathrm{OH}$ can promote the enhancement of AAR involving sympathoexcitation and hypertension. It is also possible that TNF $\alpha$ produced from other regions of the brain, or as a blood-borne cytokine crosses the circumventricular organs that lack a blood-brain barrier $(\mathrm{BBB})$, diffused into the region of the $\mathrm{PVN}$ and contributed to the AAR enhancement. Moreover, OHinduced AAR increase was attenuated by TNF blockade by using PTX systemically, a cytokine inhibitor, suggesting a role for TNFa in sympathoexcitation in $\mathrm{OH}$.

ROS can act as key modulators of increased neuronal activity in the PVN of rats with hypertension, heart failure or metabolic syndrome [29-32]. More importantly, ROS in the PVN can modulate AAR [25]. In our study, administration of TNF $\alpha$ into PVN increased the level of ROS in the PVN, and ROS clearance led to decreased AAR and sympathoexcitation caused by TNFo. TNF $\alpha$ receptor antagonist $\mathrm{R}-7050$ in the PVN also inhibited the ROS generation. Moreover, systemic administration of anticytokine agent PTX resulted in reduced AAR, SNA and ROS production in the PVN of rats with 

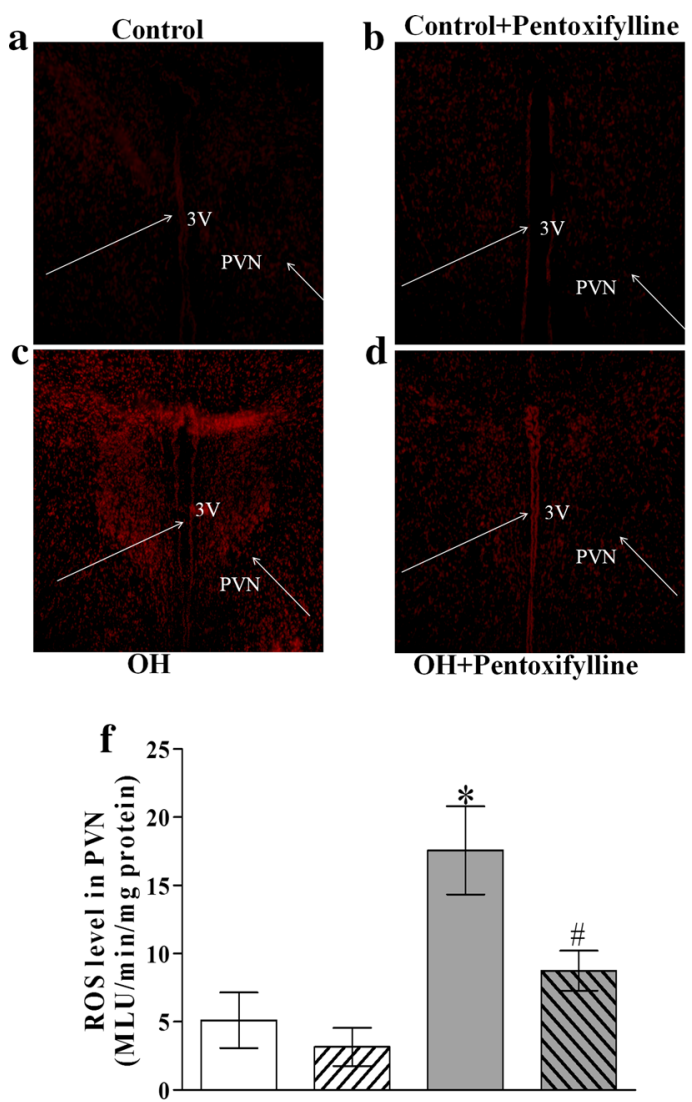

Fig. 7 The effects of chronic systemic application of pentoxifylline (PTX, a cytokine blocker, $30 \mathrm{mg} / \mathrm{kg}$, IP) for 5 weeks on the in situ ROS ( $\mathrm{n}=3$ for each group, $\mathbf{a}-\mathbf{d})$, ROS level $(n=6-7$ for each group, $\mathbf{f})$, protein expression of TNFa in the PVN ( $n=3-4$ for each group, $\mathbf{g}$ ) and TNFa content in plasma ( $n=6-7$ for each group, e). The values are mean $\pm S D ;{ }^{*} p<0.05$ versus Control; ${ }^{*} p<0.05$ versus $\mathrm{OH}$

$\mathrm{OH}$. Therefore, it is possible that the increased TNF $\alpha$ observed in the PVN can trigger ROS production that lead to AAR enhancement and sympathoexcitation in $\mathrm{OH}$.

The NADPH oxidases are one of the major sources of ROS in the PVN, and its subunits NOX2 and NOX4 in the PVN have been implicated in the development of oxidative stress and sympathoexcitation [33-35]. Furthermore, in the PVN, they were also involved in the sympathetic overactivation in rats with $\mathrm{OH}$ [25]. It is important to point out that in the PVN, TNF $\alpha$ can regulate NADPH oxidase activity to affect ROS generation [23]. TNF $\alpha$-initiated elevation of AAR in the PVN may be associated with NADPH oxidase dependent generation of ROS. In this study, TNF $\alpha$ administration into the PVN can induce the increase of NADPH oxidase activity in rats with $\mathrm{OH}$, which can be inhibited by a TNF $\alpha$ receptor antagonist. Moreover, NADPH oxidase inhibitor APO almost abolished the increases of AAR and SNA caused by TNF $\alpha$. Furthermore, the mRNA
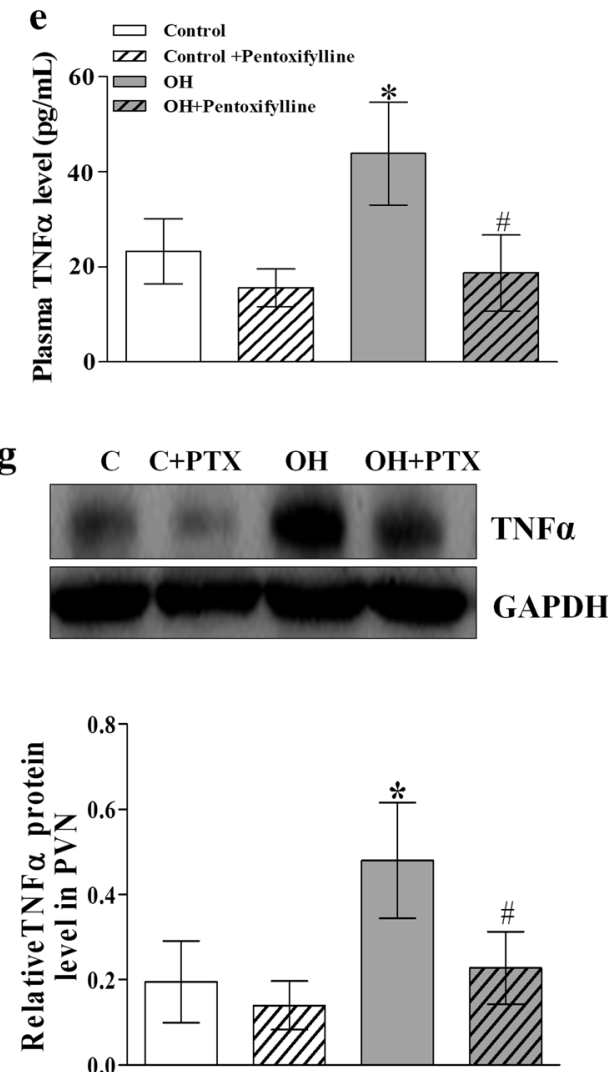

and protein expression levels of catalytic subunits of NADPH oxidase NOX2 and NOX4 and ROS content in the PVN were elevated in rats with $\mathrm{OH}$, which were significantly reduced by systemic PTX application. Taken together, these results raise the possibility that TNF $\alpha$ in the PVN induces AAR enhancement in $\mathrm{OH}$, which was mediated by the increased NADPH oxidase-dependent ROS generation.

\section{Conclusions}

The current study indicates that feeding a high-fat diet induces much more inflammatory cytokine TNF $\alpha$ production in the PVN, which activates NADPH oxidase activity to increase ROS generation for enhancing AAR, SNA and hypertension in rats with $\mathrm{OH}$. Therapeutic strategies to reduce the PVN inflammatory cytokine TNFo may play an effective role in preventing the elevation of SNA and BP in $\mathrm{OH}$. 


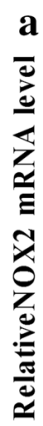

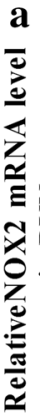

$$
\square \text { Control }
$$

107 Control +Pentoxifylline

$\square$ OH

$0.8-\square 0 \mathrm{OH}+$ Pentoxifylline

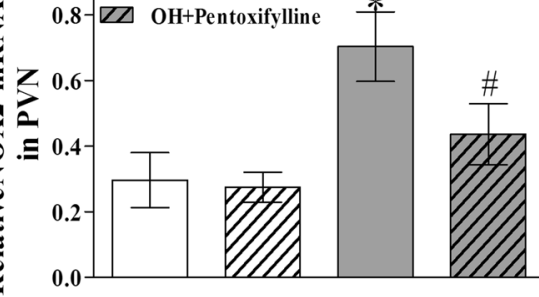

c
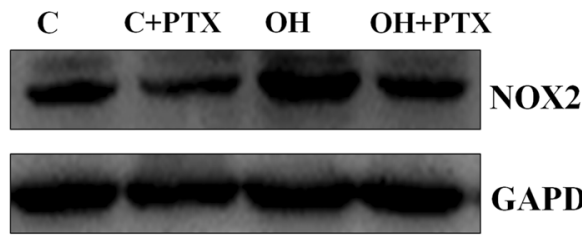

GAPDH

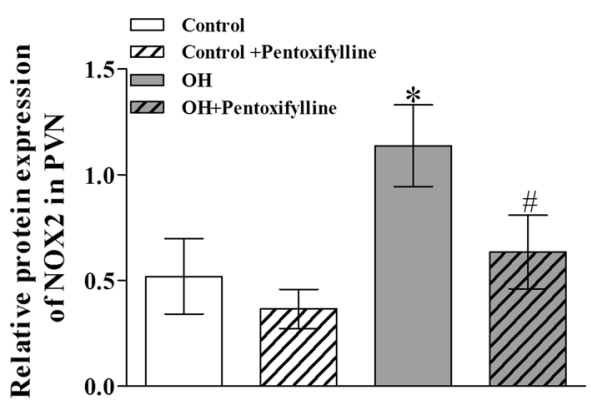

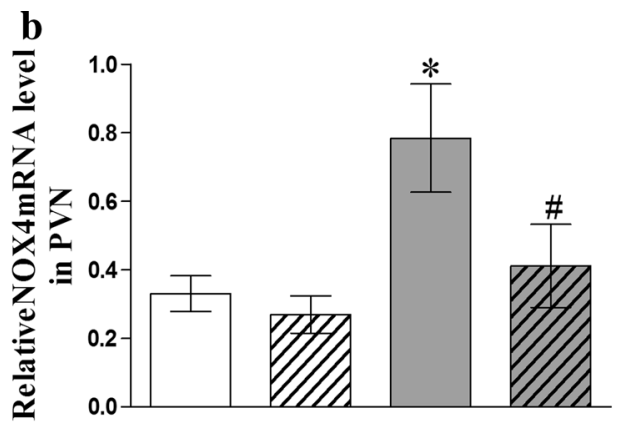

d
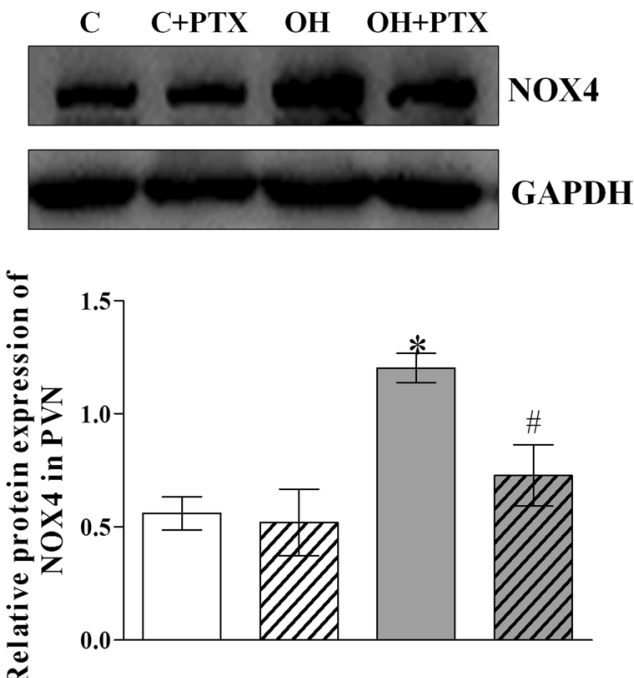

Fig. 8 The effects of chronic systemic application of pentoxifylline (PTX, a cytokine blocker, $30 \mathrm{mg} / \mathrm{kg}, \mathrm{IP}$ ) for 5 weeks on the mRNA (a, b) and protein $(\mathbf{c}, \mathbf{d})$ expressions of the NOX2 and NOX4 isoforms of NADPH oxidase. The values are mean \pm SD; ${ }^{*} p<0.05$ versus Control; ${ }^{*} p<0.05$ versus OH

\begin{abstract}
Abbreviations
AAR: adipose afferent reflex; SNA: sympathetic nerve activity; BP: blood pressure; PVN: paraventricular nucleus; TNFa: tumor necrosis factor alpha; $\mathrm{OH}$ : obesity-related hypertension; RSNA: renal sympathetic nerve activity; MAP: mean arterial pressure; CAP: capsaicin; SBP: systolic blood pressure; NE: norepinephrine; ROS: reactive oxygen species; DETC: diethyldithiocarbamate Apo: apocynin; PTX: pentoxifylline; WAT: white adipose tissue; PICs: proinflammatory cytokines; CHF: chronic heart failure; HFD: high-fat diet; BW: body weight; iWAT: inguinal WAT; DHE: dihydroethidium; GAPDH: glyceraldehyde3-phosphate dehydrogenase.
\end{abstract}

\section{Acknowledgements}

This work was supported by the National Natural Science Foundation of China (81470539 and 81600323).

\section{Authors' contributions}

YBZ designed the study. LD, YK, HBD, FZW, HZ, QG, XQX, TRS and ML performed experiments. $F Z, Y Y$ and $G Q Z$ performed the data analysis. YBZ drafted the manuscript and GQZ critically revised the manuscript. All authors read and approved the final manuscript.

\section{Availability of data and materials}

The datasets used and/or analyzed in this study will be made available by the authors on reasonable request.
Ethics approval and consent to participate

This study was carried out in accordance with the principles of the Basel Declaration and recommendations of the Experimental Animal Care and Use Committee of Nanjing Medical University, and conformed to the Guide for the Care and Use of Laboratory Animal published by the US National Institutes of Health (NIH publication, 8th edition, 2011).

\section{Consent for publication}

This study consists of animal data and is devoid of any human data.

\section{Competing interests}

The authors declare that they have no competing interests.

\section{Author details}

1 Department of Physiology, Nanjing Medical University, 101 Longmian Road, Nanjing 211166, China. ${ }^{2}$ Department of Pathophysiology, Xuzhou Medical University, Xuzhou 221004, China.

Received: 10 May 2019 Accepted: 31 July 2019

Published online: 07 August 2019

\section{References}

1. Mirza AJ, Taha AY, Khdhir BR. Risk factors for acute coronary syndrome in patients below the age of 40 years. Egypt Heart J. 2018;70:233-5. 
2. Kochli S, Endes K, Steiner R, Engler L, Infanger D, Schmidt-Trucksass A, Zahner L, Hanssen H. Obesity, high blood pressure, and physical activity determine vascular phenotype in young children. Hypertension. 2019;73:153-61.

3. Ryu S, Frith E, Pedisic Z, Kang M, Loprinzi PD. Secular trends in the association between obesity and hypertension among adults in the United States, 1999-2014. Eur J Intern Med. 2019;62:37-42.

4. Hasegawa Y, Nakagami T, Oya J, Takahashi K, Isago C, Kurita M, Tanaka Y, Ito A, Kasahara T, Uchigata Y. Body weight reduction of 5\% improved blood pressure and lipid profiles in obese men and blood glucose in obese women: a four-year follow-up observational study. Metab Syndr Relat Disord. 2019;17:250-8.

5. Jordan J, Toplak H, Grassi G, Yumuk V, Kotsis V, Engeli S, Cuspidi C, Nilsson PM, Finer N, Doehner W. Joint statement of the European Association for the Study of Obesity and the European Society of Hypertension: obesity and heart failure. J Hypertens. 2016;34:1678-88.

6. Rached MT, Millership SJ, Pedroni SMA, Choudhury Al, Costa ASH, Hardy DG, Glegola JA, Irvine EE, Selman C, Woodberry MC, et al. Deletion of myeloid IRS2 enhances adipose tissue sympathetic nerve function and limits obesity. Mol Metab. 2019;20:38-50.

7. Shi Z, Cassaglia PA, Pelletier NE, Brooks VL. Sex differences in the sympathoexcitatory response to insulin in obese rats: role of neuropeptide $Y$. J Physiol. 2019;597:1757-75.

8. Head GA, Lim K, Barzel B, Burke SL, Davern PJ. Central nervous system dysfunction in obesity-induced hypertension. Curr Hypertens Rep. 2014;16:466.

9. Zhou JJ, Yuan F, Zhang Y, Li DP. Upregulation of orexin receptor in paraventricular nucleus promotes sympathetic outflow in obese Zucker rats. Neuropharmacology. 2015;99:481-90.

10. de Kloet AD, Pati D, Wang L, Hiller H, Sumners C, Frazier CJ, Seeley RJ, Herman JP, Woods SC, Krause EG. Angiotensin type 1a receptors in the paraventricular nucleus of the hypothalamus protect against diet-induced obesity. J Neurosci. 2013;33:4825-33.

11. Chen F, Cham JL, Badoer E. High-fat feeding alters the cardiovascular role of the hypothalamic paraventricular nucleus. Am J Physiol Regul Integr Comp Physiol. 2010;298:R799-807.

12. Sun J, Ren XS, Kang Y, Dai HB, Ding L, Tong N, Zhu GQ, Zhou YB. Intermedin in paraventricular nucleus attenuates sympathoexcitation and decreases TLR4-mediated sympathetic activation via adrenomedullin receptors in rats with obesity-related hypertension. Neurosci Bull. 2019;35:34-46.

13. Shi Z, Chen WW, Xiong XQ, Han Y, Zhou YB, Zhang F, Gao XY, Zhu GQ. Sympathetic activation by chemical stimulation of white adipose tissues in rats. J Appl Physiol. 1985;2012(112):1008-14.

14. Shi H, Bartness TJ. White adipose tissue sensory nerve denervation mimics lipectomy-induced compensatory increases in adiposity. Am J Physiol Regul Integr Comp Physiol. 2005;289:R514-20.

15. Bartness TJ, Shrestha YB, Vaughan CH, Schwartz GJ, Song CK. Sensory and sympathetic nervous system control of white adipose tissue lipolysis. Mol Cell Endocrinol. 2010;318:34-43.

16. Xiong XQ, Chen WW, Han Y, Zhou YB, Zhang F, Gao XY, Zhu GQ. Enhanced adipose afferent reflex contributes to sympathetic activation in dietinduced obesity hypertension. Hypertension. 2012;60:1280-6.

17. Noratto GD, Murphy K, Chew BP. Quinoa intake reduces plasma and liver cholesterol, lessens obesity-associated inflammation, and helps to prevent hepatic steatosis in obese $\mathrm{db} / \mathrm{db}$ mouse. Food Chem. 2019;287:107-14.

18. Chen J, Bundy JD, Hamm LL, Hsu CY, Lash J, Miller ER 3rd, Thomas G, Cohen DL, Weir MR, Raj DS, et al. Inflammation and apparent treatmentresistant hypertension in patients with chronic kidney disease. Hypertension. 2019;73:785-93.

19. McCann SM, Kimura M, Karanth S, Yu WH, Mastronardi CA, Rettori V. The mechanism of action of cytokines to control the release of hypothalamic and pituitary hormones in infection. Ann N Y Acad Sci. 2000;917:4-18.

20. Song XA, Jia LL, Cui W, Zhang M, Chen W, Yuan ZY, Guo J, Li HH, Zhu GQ, Liu H, Kang YM. Inhibition of TNF-alpha in hypothalamic paraventricular nucleus attenuates hypertension and cardiac hypertrophy by inhibiting neurohormonal excitation in spontaneously hypertensive rats. Toxicol Appl Pharmacol. 2014;281:101-8.

21. Guggilam A, Cardinale JP, Mariappan N, Sriramula S, Haque M, Francis J. Central TNF inhibition results in attenuated neurohumoral excitation in heart failure: a role for superoxide and nitric oxide. Basic Res Cardiol. 2011;106:273-86.

22. Guggilam A, Haque M, Kerut EK, Mcllwain E, Lucchesi P, Seghal I, Francis J. TNF-alpha blockade decreases oxidative stress in the paraventricular nucleus and attenuates sympathoexcitation in heart failure rats. Am J Physiol Heart Circ Physiol. 2007;293:H599-609.

23. Li JM, Fan LM, Christie MR, Shah AM. Acute tumor necrosis factor alpha signaling via NADPH oxidase in microvascular endothelial cells: role of p47phox phosphorylation and binding to TRAF4. Mol Cell Biol. 2005;25:2320-30.

24. Morgan MJ, Kim YS, Liu ZG. TNFalpha and reactive oxygen species in necrotic cell death. Cell Res. 2008;18:343-9.

25. Lu QB, Sun J, Kang Y, Sun HJ, Wang HS, Wang Y, Zhu GQ, Zhou YB. Superoxide anions and $\mathrm{NO}$ in the paraventricular nucleus modulate the cardiac sympathetic afferent reflex in obese rats. Int J Mol Sci. 2017; https://doi. org/10.3390/ijms19010059.

26. Sun HJ, Zhou H, Feng XM, Gao Q, Ding L, Tang CS, Zhu GQ, Zhou YB. Superoxide anions in the paraventricular nucleus mediate cardiac sympathetic afferent reflex in insulin resistance rats. Acta Physiol. 2014;212:267-82.

27. Wang H, Li J, Gai Z, Kullak-Ublick GA, Liu Z. TNF-alpha deficiency prevents renal inflammation and oxidative stress in obese mice. Kidney Blood Press Res. 2017;42:416-27.

28. Livak KJ, Schmittgen TD. Analysis of relative gene expression data using real-time quantitative PCR and the 2(-Delta Delta C(T)) method. Methods. 2001;25:402-8.

29. Wang ML, Yu XJ, Li XG, Pang DZ, Su Q, Saahene RO, Li HB, Mao XY, Liu KL, Fu LY, et al. Blockade of TLR4 within the paraventricular nucleus attenuates blood pressure by regulating ROS and inflammatory cytokines in prehypertensive rats. Am J Hypertens. 2018;31:1013-23.

30. Su Q, Huo CJ, Li HB, Liu KL, Li X, Yang Q, Song XA, Chen WS, Cui W, Zhu $G Q$, et al. Renin-angiotensin system acting on reactive oxygen species in paraventricular nucleus induces sympathetic activation via AT1R/ PKCgamma/Rac1 pathway in salt-induced hypertension. Sci Rep. 2017;7:43107.

31. Cruz JC, Flor AF, Franca-Silva MS, Balarini CM, Braga VA. Reactive oxygen species in the paraventricular nucleus of the hypothalamus alter sympathetic activity during metabolic syndrome. Front Physiol. 2015;6:384.

32. Su Q, Qin DN, Wang FX, Ren J, Li HB, Zhang M, Yang Q, Miao YW, Yu $\mathrm{XJ}, \mathrm{Qi}$ J, et al. Inhibition of reactive oxygen species in hypothalamic paraventricular nucleus attenuates the renin-angiotensin system and proinflammatory cytokines in hypertension. Toxicol Appl Pharmacol. 2014;276:115-20.

33. Zhang Y, Yu Y, Zhang F, Zhong MK, Shi Z, Gao XY, Wang W, Zhu GQ. $\mathrm{NAD}(\mathrm{P}) \mathrm{H}$ oxidase in paraventricular nucleus contributes to the effect of angiotensin II on cardiac sympathetic afferent reflex. Brain Res. 2006;1082:132-41.

34. Xue B, Beltz TG, Johnson RF, Guo F, Hay M, Johnson AK. PVN adenovirussiRNA injections silencing either NOX2 or NOX4 attenuate aldosterone/ $\mathrm{NaCl}$-induced hypertension in mice. Am J Physiol Heart Circ Physiol. 2012;302:H733-41.

35. Infanger DW, Cao X, Butler SD, Burmeister MA, Zhou Y, Stupinski JA, Sharma RV, Davisson RL. Silencing nox4 in the paraventricular nucleus improves myocardial infarction-induced cardiac dysfunction by attenuating sympathoexcitation and periinfarct apoptosis. Circ Res. 2010;106:1763-74.

\section{Publisher's Note}

Springer Nature remains neutral with regard to jurisdictional claims in published maps and institutional affiliations. 